\title{
The Rapamycin-Sensitive Complex of Mammalian Target of Rapamycin Is Essential to Maintain Male Fertility
}

Christoph Schell, ${ }^{* \dagger \ddagger}$ Oliver Kretz, ${ }^{\circledR}$ Wei Liang, ${ }^{*}$ Betina Kiefer, ${ }^{*}$ Simon Schneider, ${ }^{*}$ Dominik Sellung, ${ }^{*}$ Tillmann Bork, ${ }^{*}$ Christian Leiber, ${ }^{\|}$Markus A. Rüegg, ${ }^{* *}$ Con Mallidis, ${ }^{\dagger \dagger}$ Stefan Schlatt, ${ }^{\dagger \dagger}$ Artur Mayerhofer, ${ }^{\ddagger \dagger}$ Tobias B. Huber, ${ }^{* \dagger \delta \xi \Phi \pi}$ and Florian Grahammer*

From the Renal Division* and Division of Urology, "University Medical Center Freiburg, Freiburg, Germany; the Spemann Graduate School of Biology and Medicine (SGBM), ${ }^{\dagger}$ the Faculties of Biology ${ }^{\ddagger}$ and Neuroanatomy, ${ }^{\S}$ the BIOSS Center for Biological Signalling Studies, ${ }^{\S \S}$ and the Center for Systems Biology

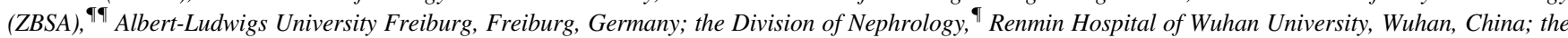
Biozentrum Basel, ** University of Basel, Basel, Switzerland; the Center for Reproductive Medicine and Andrology, ${ }^{\dagger \dagger}$ University Hospital Münster, Münster, Germany; and Anatomy III, ${ }^{\ddagger \ddagger}$ Cell Biology, Ludwig-Maximillians University Munich, Munich, Germany

\author{
Accepted for publication \\ October 21, 2015. \\ Address correspondence to \\ Tobias B. Huber, M.D., Renal \\ Division University Medical \\ Center Freiburg, Center for Clin- \\ ical Research, Breisacherstrasse \\ 66, Freiburg 79106, Germany. \\ E-mail: tobias.huber@uniklinik- \\ freiburg.de.
}

\begin{abstract}
The mammalian target of rapamycin complex 1 (mTORC1) inhibitor rapamycin and its analogs are being increasingly used in solid-organ transplantation. A commonly reported side effect is male subfertility to infertility, yet the precise mechanisms of mTOR interference with male fertility remain obscure. With the use of a conditional mouse genetic approach we demonstrate that deficiency of mTORC1 in the epithelial derivatives of the Wolffian duct is sufficient to cause male infertility. Analysis of spermatozoa from Raptor $f / / f l^{*} K s p C r e$ mice revealed an overall decreased motility pattern. Both epididymis and seminal vesicles displayed extensive organ regression with increasing age. Histologic and ultrastructural analyses demonstrated increased amounts of destroyed and absorbed spermatozoa in different segments of the epididymis. Mechanistically, genetic and pharmacologic mTORC1 inhibition was associated with an impaired cellular metabolism and a disturbed protein secretion of epididymal epithelial cells. Collectively, our data highlight the role of mTORC1 to preserve the function of the epididymis, ductus deferens, and the seminal vesicles. We thus reveal unexpected new insights into the frequently observed mTORC1 inhibitor side effect of male infertility in transplant recipients. (Am J Pathol 2016, 186: 324-336; http://dx.doi.org/10.1016/j.ajpath.2015.10.012)
\end{abstract}

Mammalian target of rapamycin complex 1 (mTORC1) is a multisubunit kinase complex integrating several nutrientdependent growth pathways and orchestrating vital cellular functions. ${ }^{1}$ Twenty-five years ago a highly specific inhibitor of mTORC1 rapamycin was first used as an immunosuppressant in solid-organ transplantation. ${ }^{2}$ Today, mTORC1 inhibitors are widely used immunosuppressants and anticancer therapeutics. ${ }^{1}$ Male infertility is a frequent and straining side effect of mTORC1 inhibitor therapy and was reported in several transplant cohorts. ${ }^{3-5}$ So far it was assumed that the antiproliferative and proapoptotic effects of rapamycin might mainly target the male testicular germ cell layer, which in turn results in oligospermia or azoospermia. ${ }^{3,6}$ Yet, despite the known sensitivity of Leydig cells to interfering agents, detected endocrine changes were variable in organ-transplanted males who were treated. ${ }^{3-5,7,8}$

Investigation of mTORC1 function in male reproductive biology has so far been mainly focused on testicular

Supported by the German Research Foundation grant CRC 1140 (F.G. and T.B.H.), and Heisenberg program grant CRC 992 (T.B.H.); the European Research Council (ERC) grant (T.B.H.); the Excellence Initiative of the German Federal and State Governments (GSC-4, Spemann Graduate School to T.B.H. and C.S., and BIOSS to T.B.H.); the BMBF-Joint transnational grant (T.B.H.); the Else-Kröner-Fresenius Stiftung (EKFS) NAKSYS stipend (C.S. and T.B.) and MOTIVATE scholarship (D.S.); the China Scholarship Council and National Natural Science Foundation of China grant 81470912 (W.L.); and a projectspecific grant support by Pfizer Pharma GmbH (formerly Wyeth GmbH) (T.B.H.).

Disclosures: T.B.H. received a project-specific grant from Pfizer Pharma $\mathrm{GmbH}$ and has acted as a consultant for Abbott Pharma, Roche, Astellas, Genzyme, and Pfizer Pharma. 
A
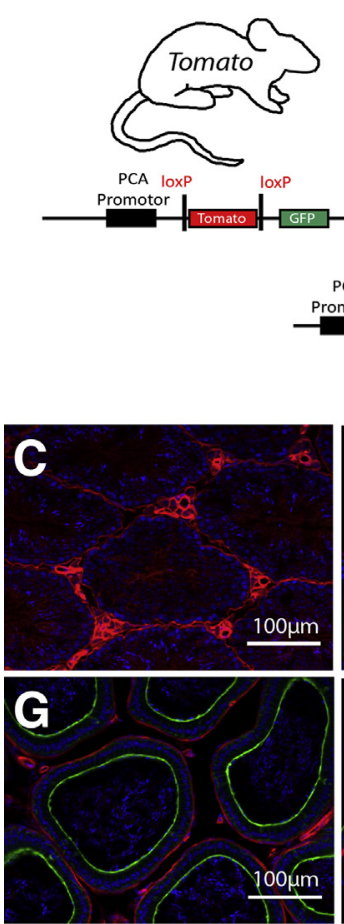

$\mathbf{K}$
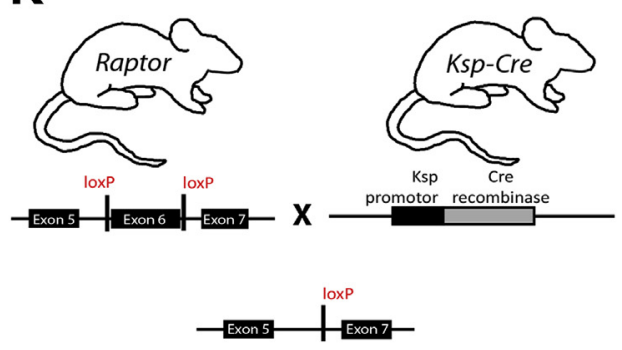

B
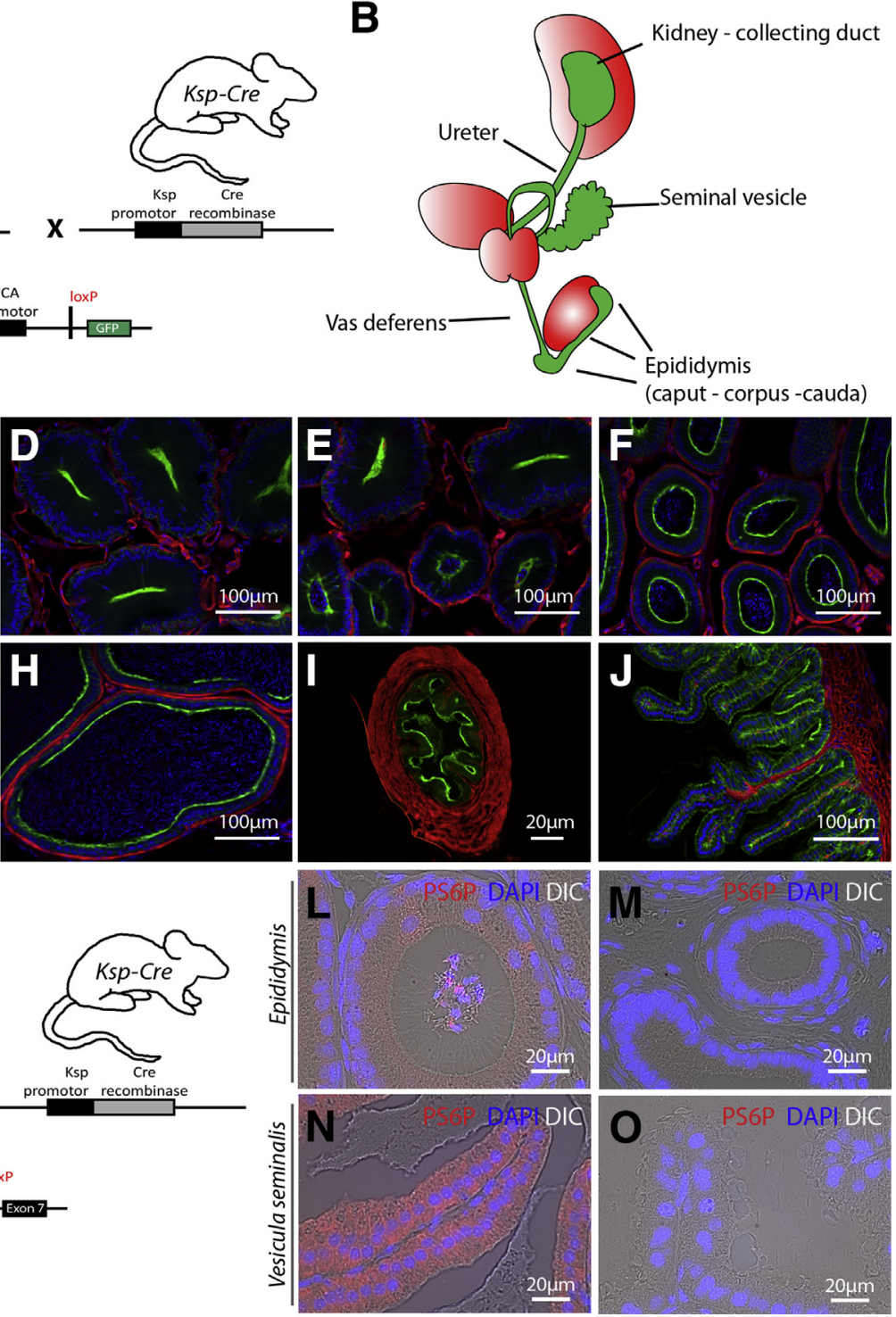

Figure 1 Targeting Raptor in derivatives of the Wolffian duct. A-J: With the use of $m T / m G$ reporter mice (A), we demonstrate that the $K s p$ promoter (B) spares testicular tissue (both germ and Leydig cells) (C) but effectively drives Cre expression in the epithelium of the ductuli efferentes (D), caput (E and $\mathbf{F}$ ) and cauda epididymidis ( $\mathbf{G}$ and $\mathbf{H}$ ), the epithelium of the ductus deferens (I), and the seminal vesicle (J) (red, tissue without Cre Expression; green, tissue with Cre expression; blue, Hoechst 33342 nuclear marker). K-0: When Raptor an essential subunit of mTORC1 is deleted with the use of KspCre mice (K), phosphorylation of S6P ( $\mathbf{L}$ and $\mathbf{N}$ ) is virtually absent in Raptor $\mathrm{fl} / \mathrm{fl}^{*} \mathrm{KspCre}$ mice (M and $\mathbf{0}$; red, PS6P; blue, Hoechst 33342; DIC overlay). DIC, differential interference contrast; GFP, green fluorescent protein; mTORC1, mammalian target of rapamycin complex 1; PCA, cytomegalovirus- $\beta$-actin enhancer-promoter; PS6P, phosphorylated S6-protein.

physiology; increased activation of mTORC1 after tuberous sclerosis 1 depletion in somatic testicular cells results in progressive germ cell loss and leads to a Sertoli cell-only phenotype. ${ }^{9}$ The stem cell factor/c-kit tyrosine kinase system is necessary for the development and maturation of functional germ cells and the maintenance of fertility. ${ }^{10} \mathrm{On}$ stimulation, the c-kit/stem cell factor receptor induces activation of the phosphatidylinositol 3-kinase pathway, which is essential to propagate proliferation and to prevent apoptosis in early spermatogonial cells. Indeed, male mice with genetic deletion of the phosphatidylinositol 3-kinase binding site in the c-kit/stem cell factor receptor are sterile, owing to a block in spermatogenesis, with decreased proliferation and subsequent extensive apoptosis occurring at the spermatogonial stem cell level. ${ }^{10}$ mTORC1 and p70S6K act downstream of AKT and mediate primordial germ cell growth in vitro. ${ }^{11} \mathrm{Be}-$ sides direct effects on primordial germ cells a study implicated mTORC1 signaling in the regulation of the blood-testis barrier within the seminiferous tubules. ${ }^{12}$ Nevertheless, insights into the role of mTORC1 in nontesticular male reproductive tissue are lacking and might provide further insights to explain the male subfertility to infertility observed under rapamycin treatment. 
A

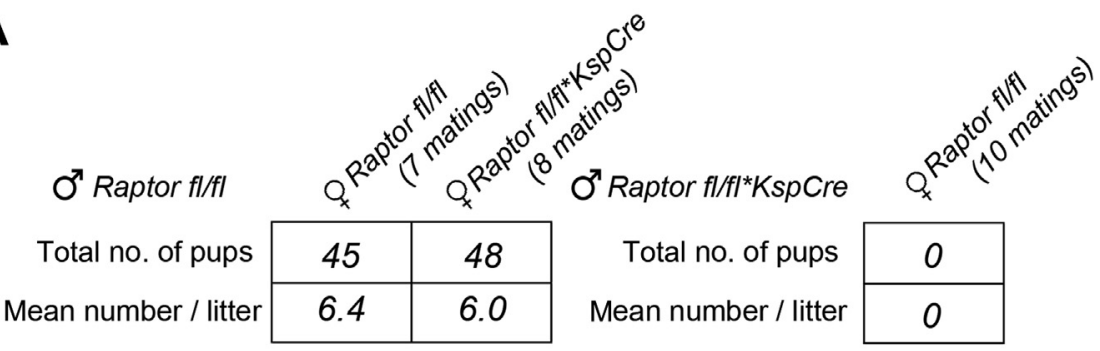

B
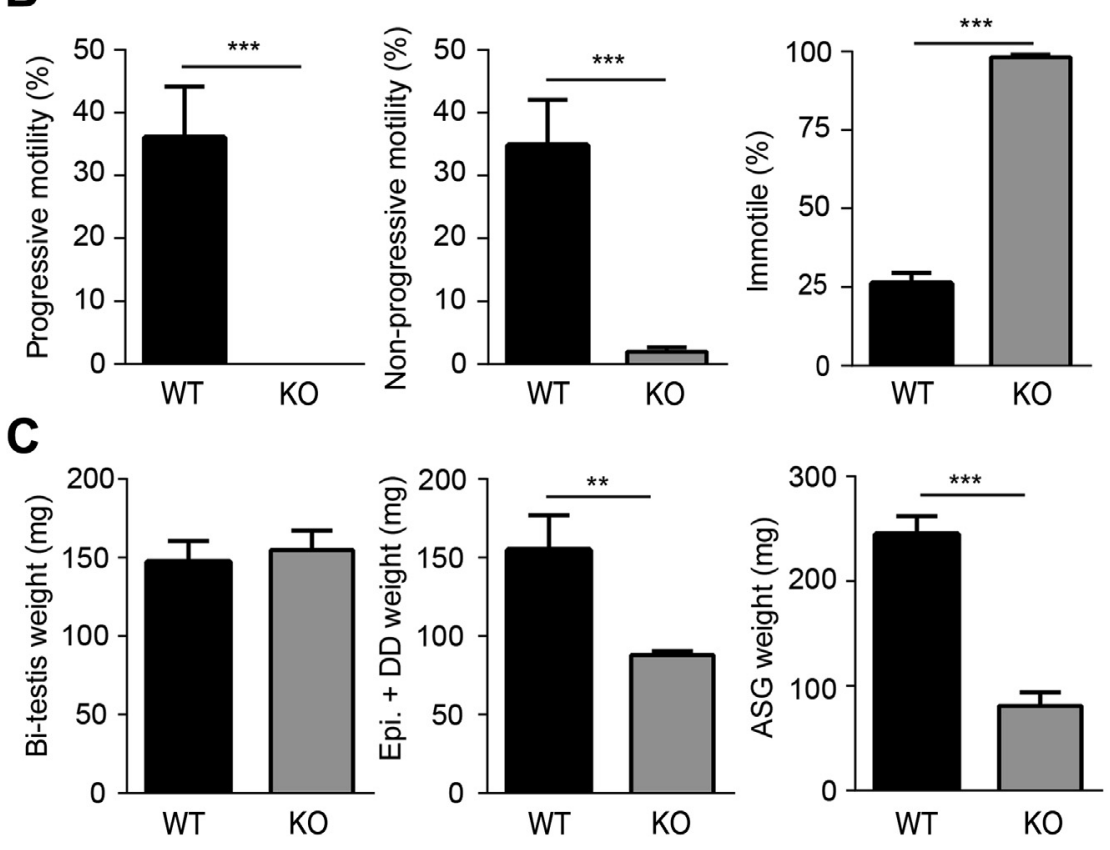

Figure 2 Male Raptor $f l / f l^{*} K s p C r e$ are infertile and have severe sperm abnormalities. A: Although Raptor-deficient female mice only show a slight reduction of pups per litter, Raptor-deficient males do not produce any offspring. B: The percentage of progressive and nonprogressive motility dramatically reduces in Raptor-deficient mice; however, the percentage of immotile sperm increases correspondingly. C: Compared with control mice Raptor-deficient mice show a reduced weight of the epididymis and ductus deferens and of the associated sexual glands, whereas bi-testis weight is indistinguishable between genotypes. $n=9$ mice per genotype (B); $n=8$ mice per genotype, except for epididymis $n=3$ (C). ${ }^{* *} P<0.01$, ${ }^{* * * P}<0.001$. ASG, associated sexual glands; DD, ductus deferens; Epi, epididymis; KO, knockout; WT, wild-type.

\section{Materials and Methods}

\section{Animals}

All animal experiments were conducted according to the NIH Guide for the Care and Use of Laboratory Animals, ${ }^{13}$ and the German law for the welfare of animals and were approved by local authorities (Regierungspräsidium Freiburg G-10/39). Mice were housed in a specific pathogen-free facility with free access to chow and water and a 12-hour day/night cycle. Breeding and genotyping were performed according to standard procedures. Raptor $f / f l$ mice were described previously $^{14}$ and were crossed to KspCre mice. ${ }^{15} \mathrm{mT} / \mathrm{mG}$ mice $\left[G t(2) 26 \operatorname{Sor}^{t m 4(A C T B-t d T o m a t o,-E G F P) L u o} / \mathrm{J}\right]$ were purchased from The Jackson Laboratory (Bar Harbor, ME) ${ }^{16}$ Rapamycin for i.p. injections (R-5000; LC Lab, Woburn, MA) was diluted in a mix of PEG400 and Tween-80. Injections were performed every 48 hours at a dose of $10 \mathrm{mg} / \mathrm{kg}$ body weight for a total period of 3 weeks. Trough values were performed at the end of the experiment 48 hours after the last administration.

\section{Breeding Efficiency}

Male Raptor $f l f l^{*} K s p C r e$ and Raptor fl/fl (control) mice were timed mated with female Raptor $f / f l$ and
Raptor $f / f * K s p C r e$ mice, and the number of resultant offspring was noted.

\section{Sperm Analysis}

For sperm analysis at least nine mice of each genotype (Raptor fl/fl and Raptor $f / f{ }^{*} K s p C r e$ ) were analyzed. After mice were sacrificed by cervical dislocation the testis, epididymis, and vas deferens were immediately dissected in prewarmed $0.9 \%(\mathrm{w} / \mathrm{v}) \mathrm{NaCl}$ (analyzed mice were age matched and sacrificed at 4 months). The caput epididymis was then gently scraped with needles to allow spermatozoas to swim out into $500 \mu \mathrm{L}$ of cpm solution for 5 minutes [MTG from Sigma M-6145, finally diluted $1: 25,000$ in filtered raffinose $18 \%(\mathrm{w} / \mathrm{v})$ and $3 \%(\mathrm{w} / \mathrm{v})$ skim milk powder]. After this swim-out phase the sperm suspension was further diluted with human tubal fluid medium (including bovine serum albumin and glucose), kept at $37^{\circ} \mathrm{C}$, and further analyzed by using a computeraided sperm analysis system (version 10.7; HamiltonThorne Biosciences, Beverly, MA). Nonprogressive and progressive spermatozoa were included in the analysis. The following variables were measured: total and progressive motility (including straight progressive 


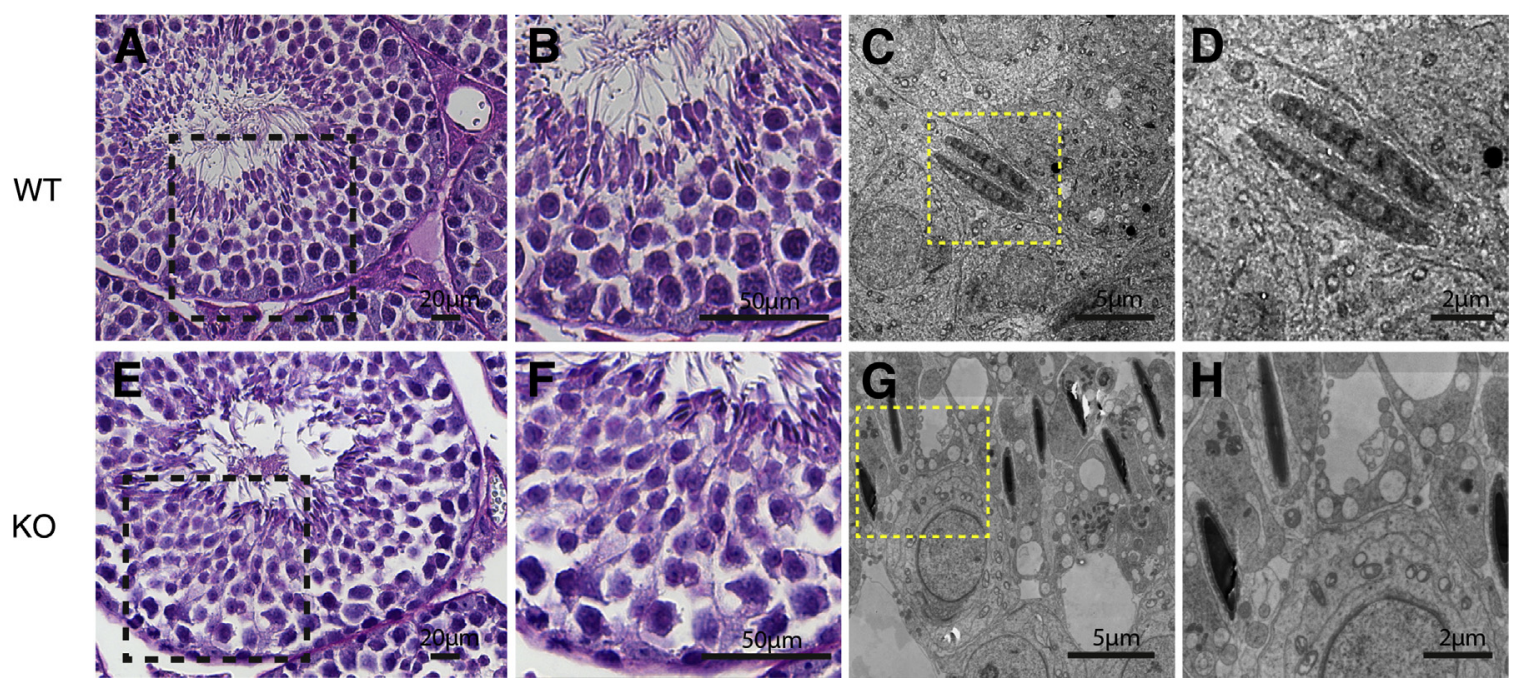

Figure 3 Light microscopically the germ cell layer is intact in Raptor $f / / f l^{\star} K s p$ Cre mice. Light microscopy of seminiferous tubules of WT mice (A and $\mathbf{B}$; black dotted lines in $\mathbf{A}$ represent magnified detail in $\mathbf{B}$ ) and Raptor-deficient mice (E and $\mathbf{F}$; black dotted lines in $\mathbf{E}$ represent magnified detail in $\mathbf{F}$ ) shows normal spermatogenesis. Ultrastructurally, Raptor-deficient mice ( $\mathbf{G}$ and $\mathbf{H}$; yellow dotted lines in $\mathbf{G}$ represent magnified detail in $\mathbf{H})$ present with vacuolization in the germinal epithelium, likely secondary to obstruction in more distal sperm-transporting ducts, which is not apparent in control mice (C and $\mathbf{D}$; yellow dotted lines in C represent magnified detail in D). KO, knockout; WT, wild-type.

and nonstraight progressive spermatozoa) and immotile spermatozoa.

\section{Morphologic Analysis}

For KspCre expression analysis $m T / m G^{*}$ KspCre mice were perfused transcardially with $4 \%(\mathrm{w} / \mathrm{v})$ paraformaldehyde (PFA) in phosphate buffer in deep anesthesia (Ketanest/ Rompun; Bayer, Leverkusen, Germany). The whole urogenital tract was removed and incubated with $4 \%(\mathrm{w} / \mathrm{v})$ PFA in phosphate buffer at $4^{\circ} \mathrm{C}$ for 3 hours. Individual organs were immersed in $15 \%(\mathrm{w} / \mathrm{v})$ sucrose in phosphatebuffered saline for 2 hours and 30\% (w/v) sucrose overnight, then frozen in OCT compound (Sakura Finetek, Torrance, CA) and sectioned at $6 \mu \mathrm{m}$ (Leica Kryostat, Wetzlar, Germany). For paraffin embedding Raptor $\mathrm{fl}$ $f{ }^{*} K s p C r e$ and Raptor $f l f l$ mice were perfused as described. The urogenital tract was incubated in 4\% PFA for 24 hours and then dehydrated in ethanol. Periodic acid-Schiff staining was performed on $3-\mu \mathrm{m}$ thick sections. For electron microscopy mice were deeply anesthetized with $50 \mathrm{mg} / \mathrm{kg}$ body weight sodium pentobarbital and transcardially perfused with $4 \%$ PFA and $1 \%(\mathrm{v} / \mathrm{v})$ glutaraldehyde in 0.1 $\mathrm{mol} / \mathrm{L}$ phosphate buffer. The testis, epididymis, and seminal vesicles were removed and postfixed in the same fixative (overnight at $4^{\circ} \mathrm{C}$ ). After postfixation, tissue blocks were washed in $0.1 \mathrm{~mol} / \mathrm{L}$ phosphate buffer, treated with osmium tetroxide ( $1 \%$ for 45 minutes), and stained with uranyl acetate (1\% w/v in $70 \% \mathrm{v} / \mathrm{v}$ ethanol). After dehydration tissue blocks were flat-embedded in epoxy resin (Durcupan ACM; Sigma-Aldrich, Gillingham, United Kingdom). Ultrathin sections $(40 \mathrm{~nm})$ were cut on an ultracut (Leica, Wetzlar, Germany) and analyzed with the use of an $80 \mathrm{kV}$ Zeiss Leo transmission electron microscope (Zeiss, Oberkochen, Germany).

\section{Isolation of PEECS}

Culture of primary epididymal epithelial cells (PEECs) was performed as previously described with some minor modifications. ${ }^{17,18}$ In brief, 6- to 8-week-old male mice were sacrificed by cervical dislocation, and epididymides were dissected (initial experiments were performed with the use of $m T / m G^{*} \mathrm{KspCre}$ mice to evaluate the purity and efficiency of epithelial cell outgrowth). Adventitia and adhering fat were removed, and the epididymis was cut into smaller pieces. An enzymatic digestion was applied to the tissue fragments for 30 minutes at room temperature. The digest solution consisted of $2 \mathrm{mg} / \mathrm{mL}$ Typ II Worthington Collagenase (Worthington, Lakewood, NJ), $1 \mathrm{mg} / \mathrm{mL}$ Protease (Sigma, Schnelldorf, Germany), and $100 \mathrm{U} / \mathrm{mL}$ DNase I (Applichem, Darmstadt, Germany). During enzymatic digestion, a mechanical dissociation step was applied every 10 minutes with the use of cut $1-\mathrm{mL}$ pipette tips. After completion of the digest, the solution was filtered with the use of $70-\mu \mathrm{m}$ cell strainers (Corning, Kaiserslautern, Germany) and pelleted by centrifugation at $500 \times g$ for 10 minutes. The resulting pellet was resuspended in culture media, and the solution was seeded on Primaria 6-well plates (Corning). The full culture medium consisted of Iscove's modified Dulbecco's medium (Gibco-Life Technologies, Darmstadt, Germany) that was supplemented with $50 \mathrm{U} / \mathrm{mL}$ penicillin; $50 \mu \mathrm{g} / \mathrm{mL}$ streptomycin; $10 \mu \mathrm{g} / \mathrm{mL}$ insulin, transferrin, and selenite (Roche, Mannheim, Germany); $1 \mu \mathrm{g} / \mathrm{mL}$ retinoic acid (Calbiochem, Sandhausen, Germany); $10 \mathrm{nmol} / \mathrm{L}$ hydrocortisone; and $100 \mathrm{nmol} / \mathrm{L}$ 


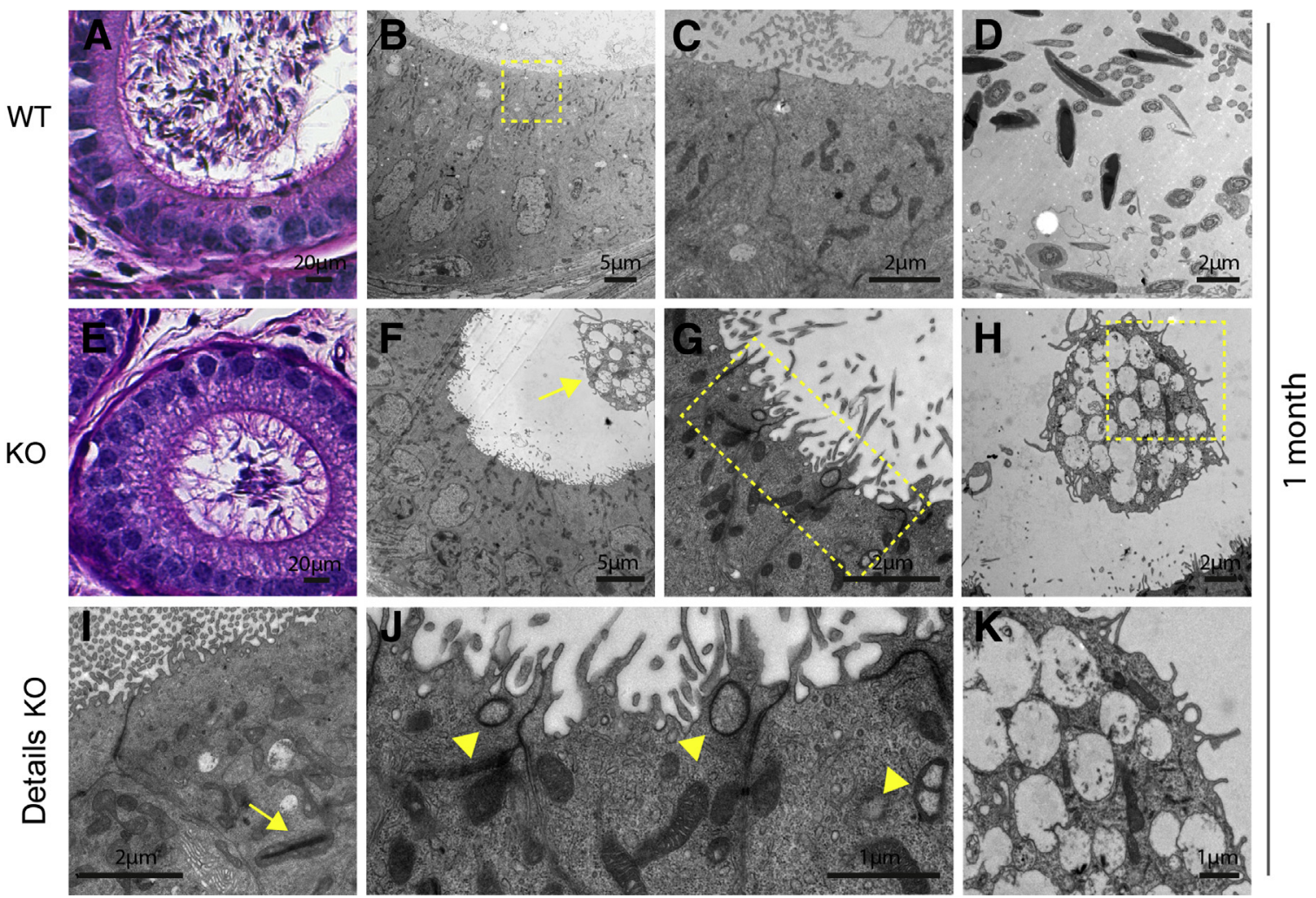

Figure 4 Raptor $f l f l^{\star} K s p C r e$ mice present with increased epididymal spermiophagy at 1 month of age. Light microscopy of the caput epididymidis in 1 month-old mice apparently shows fewer spermatozoa in Raptor K0 mice than in control mice (A and $\mathbf{E})$. Transmission electron microscopy shows unremarkable epithelial and sperm structure in the lumen of control mice (B-D; yellow dotted lines in B represent magnified detail in $\mathbf{C}$ ), whereas Raptor-deficient mice present with intraluminal spermiophages $(\mathbf{F}, \mathbf{H}$, and $\mathbf{K}$; yellow arrow in $\mathbf{F}$ indicates spermiophage; yellow dotted lines in $\mathbf{H}$ represent magnified detail in $\mathbf{K}$ ), endocytosed, degraded sperm (I, yellow arrow), and epithelial cells that contain enlarged endosomal vesicles close to the apical membrane (G and $\mathbf{J} ;$ yellow dotted lines in $\mathbf{G}$ represent magnified detail in $\mathbf{J}$; yellow arrowheads indicate endosomal vesicles). K0, knockout; WT, wild-type.

dihydrotestosterone (Sigma, Schnelldorf, Germany). Cells were cultured under standard conditions in a humidified incubator at $37^{\circ} \mathrm{C}$ with $5 \% \mathrm{CO}_{2}$. Culture medium was exchanged every 48 hours. Inhibition with rapamycin was performed either for 24 or 72 hours under full medium conditions (final concentration, $100 \mathrm{nmol} / \mathrm{L}$ rapamycin in solution; Calbiochem; dimethyl sulfoxide served as a control). For immunofluorescence staining of PEECs, cells were trypsinized and transferred into collagen IV-coated microchambers (ibidi $\mu$-slides, ibidi, Munich, Germany).

\section{Western Blot Analysis}

Protein lysates from vesicula seminalis and testis were generated by glass-glass homogenization in RIPA lysis buffer that contained Roche complete protease inhibitor cocktail (Roche). Lysates were centrifuged $(15,000 \times g, 15$ minutes, $4^{\circ} \mathrm{C}$ ), and protein concentration was measured with the use of the BCA protein quantification kit (Pierce, Darmstadt, Germany). The different samples were separated on an SDS gel, transferred on a membrane with the use of the i-Blot technology (Invitrogen, Carlsbad, CA), and subsequently analyzed with standard techniques. Harvested PEECs were also lyzed with RIPA buffer, measured as indicated above, and further analyzed. The following antibodies were used: anti-phosphorylated S6protein (PS6P; dilution 1:1000; 2211, rabbit; Cell Signaling, Danvers, MA); anti-phospho-extracullular signal-regulated kinase 1/2 (dilution 1:1000; 4377, rabbit; Cell Signaling); antiandrogen receptor (dilution 1:1000; SC-816, rabbit; Santa Cruz Biotechnologies, Dallas, TX), and CALNEXIN (dilution 1:1000; ADI-SPA-860-J, rabbit; Enzo Life Sciences, Loerrach, Germany).

\section{Seahorse XFp Mitochondrial Analysis of PEECs}

Optimization of cell density for PEECs and optimization of the working concentration of each individual inhibitor was performed before Seahorse XFp experiments according to the Seahorse XFp User's Manual (Seahorse Bioscience, Billerica, MA). Cells were seeded at a density of 20,000 cells/well. The Seahorse XFp mitochondrial stress test was conducted according to the manufacturer's instruction. Specifically, PEECs on XFp microplates were rinsed once. $\mathrm{XF}$ assay buffer was added. Afterward the plate was equilibrated for 1 hour at $37^{\circ} \mathrm{C}$ in a non- $\mathrm{CO}_{2}$ incubator. All medium and solutions of mitochondrial complex inhibitors were adjusted to $\mathrm{pH} 7.4$ on the day of the assay. After five baseline measurements of oxygen consumption rate, inhibitors of the respiratory chain were sequentially injected 

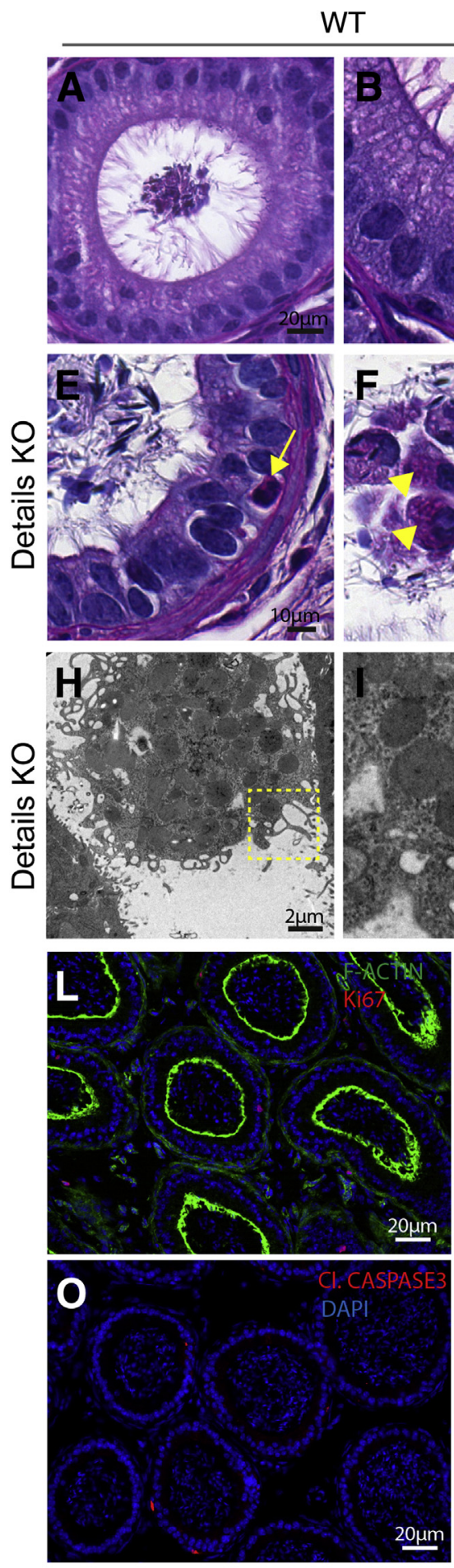

WT
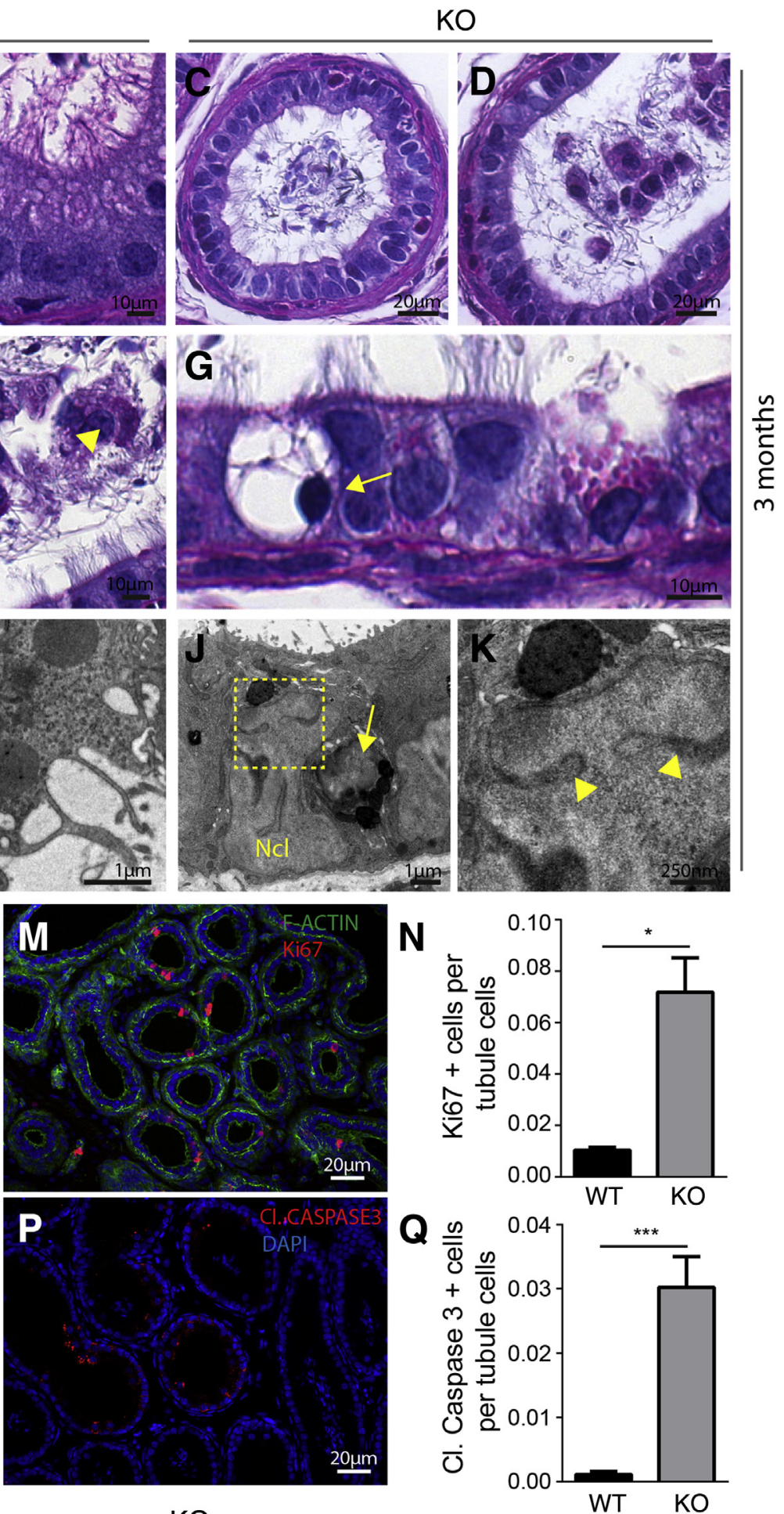

Figure 5 Severe epithelial damage and numerous spermiophages in 3-month-old Raptor $f l / f l{ }^{\star} K s p C r e$ mice. A-F: At 3 months of age, epithelial structure looks completely unremarkable in control mice (A and B), whereas KO mice show increased amounts of epididymal epithelial cell detritus within the epididymis lumen (C, D, and F; yellow arrowheads pointing toward detached epithelia and spermiophages), pyknotic cell nuclei within the epithelial layer (E, yellow arrow). G: In some areas cellular ghosts with remaining nuclei but lost cytoplasm are evident (yellow arrow). H-K: Ultrastructurally numerous spermiophages within the epididymal lumen can be detected ( $\mathbf{H}$ and $\mathbf{I}$; yellow dotted lines in $\mathbf{H}$ represent magnified detail in $\mathbf{I}$ ), whereas damaged epithelial cells show nuclear inclusions and nuclear membrane infoldings ( $\mathbf{J}$ and $\mathbf{K}$; yellow dotted lines in $\mathbf{J}$ represent magnified detail in $\mathbf{K}$; yellow arrow indicates nuclear inclusions; yellow arrowheads in $\mathbf{K}$ indicate nuclear infoldings). $\mathbf{L}-\mathbf{N}$ : Epithelial proliferation is strikingly increased in Raptor $\mathrm{fl} / \mathrm{fl}^{*} \mathrm{KspCre}$ mice compared with control mice. $\mathbf{0} \mathbf{- Q}$ : Similarly, apoptosis increases after Raptor deletion. $n=3$ mice per genotype $(\mathbf{L}-\mathbf{N}) ; n=3$ mice, at least 65 tubules per animal and genotype $(\mathbf{0}-\mathbf{Q}) .{ }^{*} P<0.05,{ }^{* *} P<0.001$. Cl, cleaved; K0, knockout; Ncl, nucleus; WT, wild-type. 

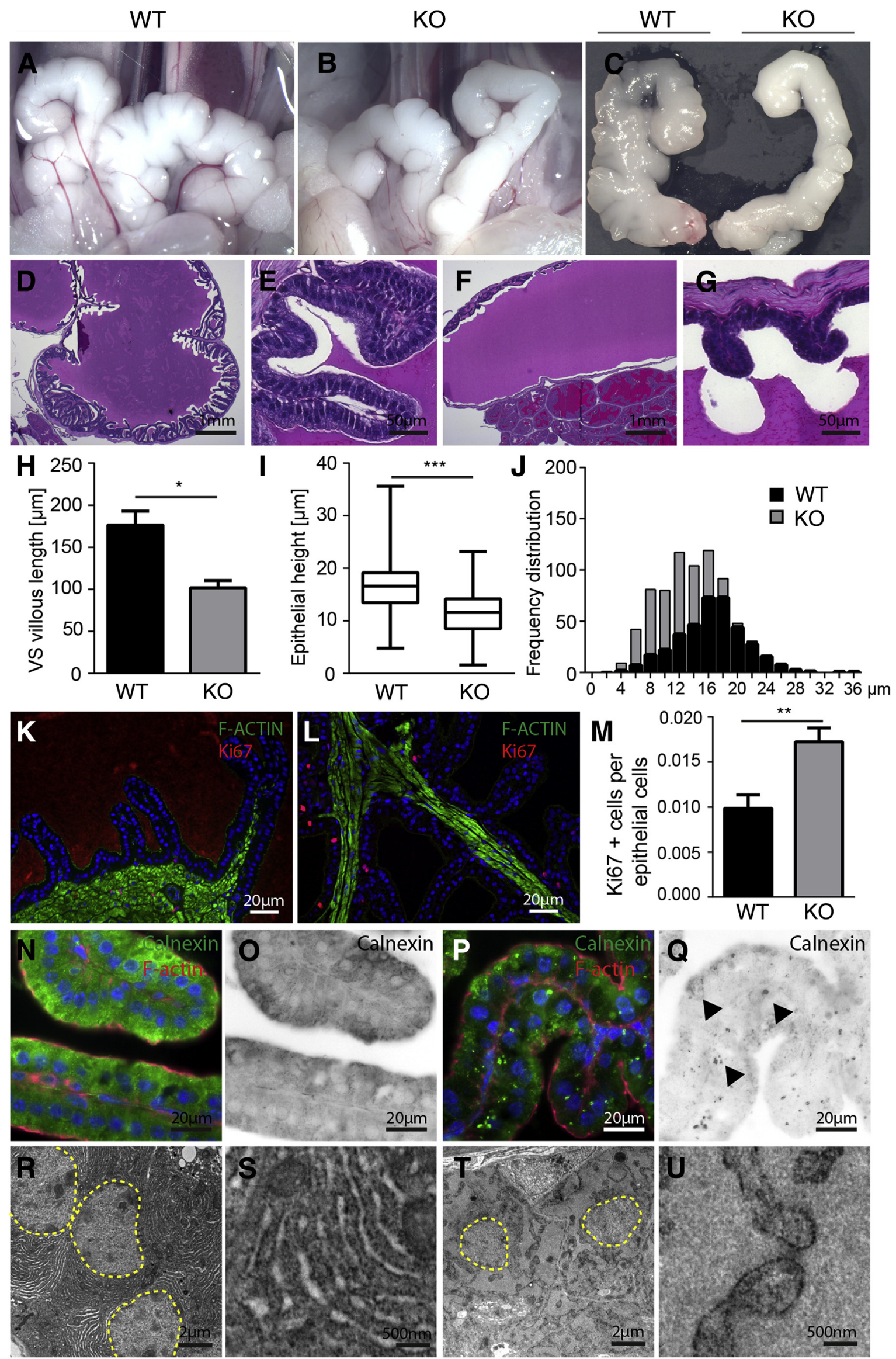
into each well. Three oxygen consumption rate readings were taken after the addition of each inhibitor and before the automated injection of the subsequent inhibitor. Mitochondrial complex inhibitors, in order of injection, included $2 \mu \mathrm{mol} / \mathrm{L}$ oligomycin to inhibit complex $\mathrm{V}, 1 \mu \mathrm{mol} / \mathrm{L}$ carbonyl cyanide-4-(trifluoromethoxy)phenylhydrazone to uncouple the proton gradient, $1.0 \mu \mathrm{mol} / \mathrm{L}$ antimycin A (inhibitor of complex III), and $1.0 \mu \mathrm{mol} / \mathrm{L}$ rotenone (complex I inhibitor). Oxygen consumption rate and extracellular acidification rate were automatically calculated by Seahorse XFp software version 2.2.0 (Seahorse Bioscience). After each experiment cells were fixed with PFA, and nuclei were stained with DAPI. All XFp plates were scanned with an Olympus ScanR Screening Station for high-throughput microscopy detection (Olympus, Tokyo, Japan). Cell number was assessed to normalize Seahorse analysis data with the use of ScanR Analysis software version 1.2.0.6 (Olympus). Seahorse XFp measurements were normalized and further processed with Seahorse XFp software version 2.2 (Seahorse Bioscience) and Excel 2010 (Microsoft, Redmond, WA). Results of all experiments are presented as means \pm SD, unless otherwise specified.

\section{Immunofluorescence Staining of Histology Sections and Primary Cells}

The sections of $m T / m G$ reporter mice were counterstained with Hoechst 33342 (Life Technologies, Karlsruhe, Germany). Immunofluorescence on cryo-embedded tissue was performed as previously described. ${ }^{19}$ In brief, sections were postfixed with PFA $4 \%$ for 3 minutes, blocked with 5\% bovine serum albumin for 1 hour, and consecutively incubated with primary and secondary antibodies for 1 hour and 20 minutes, respectively, at room temperature. For CLUSTERIN and cleaved-CASPASE 3 staining antigen retrieval on paraffin sections was performed with $\mathrm{pH} 6$ citrate buffer and $\mathrm{pH} 9$ EDTA buffer, respectively. PEECs were fixed with prewarmed $4 \%$ PFA in phosphate-buffered saline for 10 minutes, followed by permeabilization with $0.1 \%$ Triton X-100 for 3 minutes, and blocked in 5\% bovine serum albumin for 1 hour. Antibodies were incubated for 1 hour at room temperature. The following primary antibodies were used: rabbit anti-CALNEXIN (dilution 1:100; ADISPA-860-J; Enzo Life Sciences), rabbit anti-Ki67 (RM9106-S0; Thermo Fisher Scientific, Karlsruhe, Germany), rabbit anti-cleaved CASPASE 3 (dilution 1:100; 9664; Cell Signaling), rabbit anti-androgen receptor (dilution
1:100; SC-816, rabbit; Santa Cruz Biotechnologies, Dallas, TX), rabbit anti-pS6P (dilution 1:100; 2211; Cell Signaling), rabbit anti-P-Ser473 AKT (dilution 1:100; 4060S; Cell Signaling), goat anti-CLUSTERIN (dilution 1:100; SC-6419 C-18; Santa Cruz Biotechnologies, Torrance, CA), rabbit anti-CRISP1 (HPA028445; Human Protein Atlas, Stockholm, Sweden), rabbit anti-SERPINF1 (HPA005825; Human Protein Atlas). Secondary antibodies were Alexa 488 anti-rabbit, Alexa 555 anti-rabbit, Alexa 555 anti-goat, Alexa 488 Phalloidin, Alexa 555 Phalloidin (Life Technologies). Images were taken on a Zeiss fluorescence microscope equipped with a $5 \times, 20 \times$, and $63 \times$ objective and an ApoTOME device (Zeiss, Oberkochen, Germany).

\section{Quantification of Image Data}

Quantification of proliferation (Ki-67) and apoptosis (cleaved CASPASE 3) was performed on tissue sections from three to four mice per genotype. Images of immunofluorescence staining were acquired with a $20 \times$ objective on a Zeiss Axioplan2 microscope. At least 10 images were recorded and segmented semiautomatically. For epididymis sections individual tubules (at least 20 tubules per mouse) were segmented, and absolute nuclei counts and tubule section area were measured with a custom macro implemented in ImageJ software version 4.1x (NIH, Bethesda, MD; http://imagej.nih.gov/ij). A similar method was applied for quantification of proliferating and apoptotic nuclei on vesicula seminalis sections. Villous length and epithelial height measurements (at least 250 individual epithelial cells per mouse) were performed on randomly chosen sections with the use of ImageJ. For the quantification of CLUSTERIN vesicles images were background filtered and manually thresholded, and vesicles were measured with the particle analyzer function of ImageJ. At least 500 vesicles averaged from three individual mice per genotype were analyzed. Quantification of the aspect ratio to assess mitochondrial structure was performed on randomly chosen electron microscopy images. Longest and smallest diameter of individual mitochondria was quantified on approximately 600 individual mitochondria of two mice per genotype.

\section{Statistical Analysis}

Data are expressed as means \pm SEM, except for the Seahorse XFp data that are presented as means \pm SD. Statistical comparisons were performed with the GraphPad Prism Software Package 6 (GraphPad Software Inc., La

\footnotetext{
Figure 6 Translational activity in epithelial cells of the seminal vesicle are greatly reduced in Raptor $f l f l^{\star} K s p C r e$. A-C: Macroscopically, the seminal vesicles of 3-month-old Raptor fl/fl*KspCre mice shrink, are less arborated, and severely indurated compared with age-matched WT males. D-G: These changes are recapitulated histologically, where the degree of epithelial fold formation is greatly reduced and the epithelial cells themselves appear condensed (F and $\mathbf{G}$ ) compared with their WT counterparts ( $\mathbf{D}$ and $\mathbf{E})$. $\mathbf{H}-\mathbf{J}$ : Assessment of villous length and epithelial height prove these observations. $\mathbf{K}-\mathbf{M}$ : Similar to the epididymis, proliferation increases in $\mathrm{KO}$ mice compared with control mice. $\mathbf{N}-\mathbf{Q}$ : The ER marker CALNEXIN shows a widespread, homogenous staining pattern in WT mice ( $\mathbf{N}$ and $\mathbf{0})$, whereas punctate clustering is observed in $\mathrm{KO}$ mice ( $\mathbf{P}$ and $\mathbf{Q}$; arrowheads indicate clustered signal pattern). $\mathbf{R}-\mathbf{U}$ : Ultrastructurally, WT cells show a densely packed ER ( $\mathbf{R}$ and $\mathbf{S}$; yellow dotted lines indicate nuclei) which only appears as small remnants in $\mathrm{KO}$ mice ( $\mathbf{T}$ and $\mathbf{U}$; yellow dotted lines indicate nuclei). $n=50$ villi averaged over 3 mice per genotype $(\mathbf{H}-\mathbf{J}) ; n=750$ individual epithelial cells for epithelial height measurements $(\mathbf{H}-\mathbf{J}) ; n=3$ mice per genotype $(\mathbf{K}-\mathbf{M}) .{ }^{*} P<0.05,{ }^{*} P<0.01$, and ${ }^{* *} P P<0.001$. ER, endoplasmatic reticulum; K0, knockout; VS, vesicula seminalis; WT, wild-type.
} 

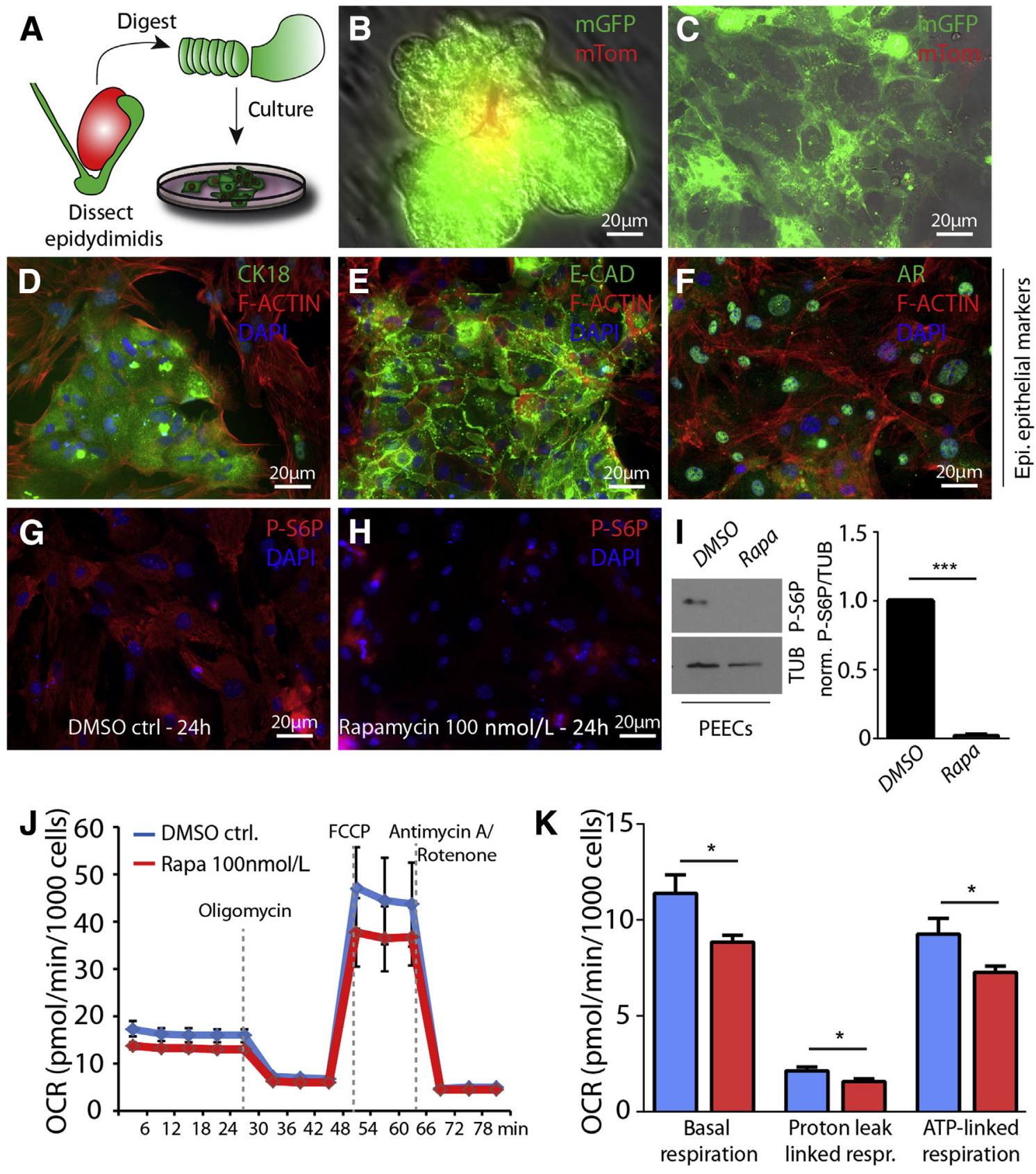

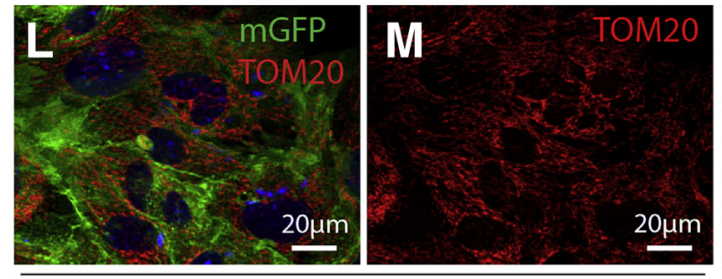

DMSO ctrl - 72h
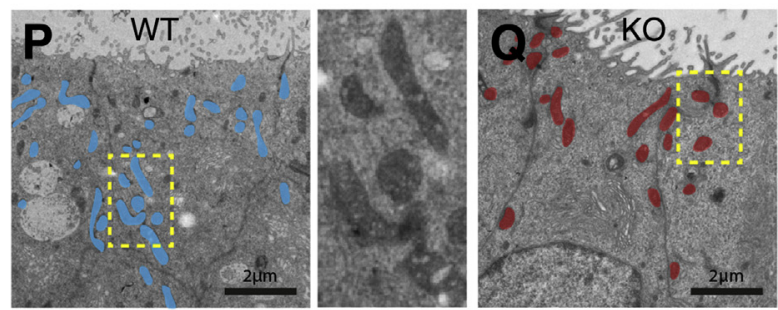
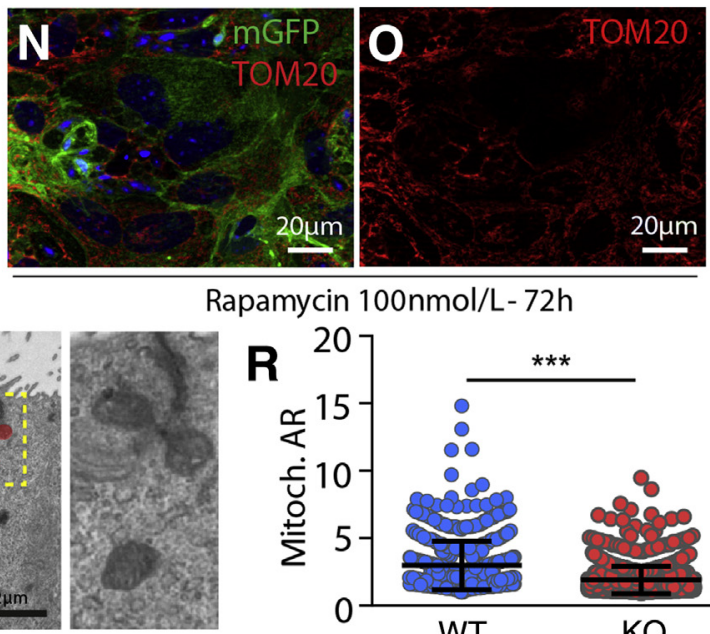

Rapamycin 100nmol/L- $72 \mathrm{~h}$

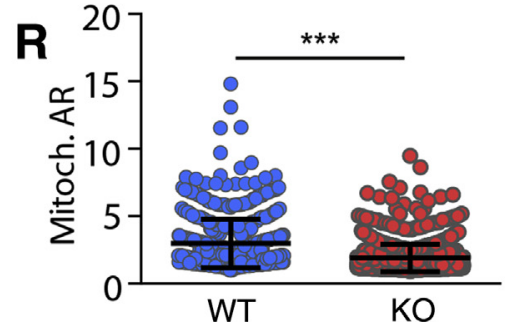


Jolla, CA) with two-tailed Student's $t$-test or the nonparametric $U$ test. Differences with $P<0.05$ were considered significant.

\section{Results}

We observed that mTORC1 deficiency in derivatives of the Wolffian duct was sufficient to cause male but not female infertility. Analysis of the Ksp-promotor driven Cre expression in male mice revealed a completely penetrant reporter signal in epithelial cells from the epididymis, ductus deferens, and the seminal vesicles, which all represent derivatives of the Wolffian duct (Figure 1, A, B, D-J). No green fluorescent protein-positive reporter signal was detected in the testis or spermatozoa (Figure 1, B, C, G, and $\mathrm{H})$. Expression in the female reproductive tract was detected in derivatives of the Mullerian duct, but penetrance seemed to be less compared with males (Supplemental Figure S1). Although Raptor $f / f l$ mice showed a strong P-S6P staining in epithelial cells lining the epididymis and vesicula seminalis, this mTORC1 downstream signal was virtually absent in Raptor $f / f f * K s p C r e$ males (Figure $1, \mathrm{~K}-\mathrm{O}$ ). In a compensatory fashion mTORC2-dependent phosphorylation of P-Ser473AKT increased in these tissues (Supplemental Figure S2, A-D). Androgen receptor expression was not effected in both vesicula seminalis and epididymis of Raptor $f l f l^{*} K s p C r e$ mice (Supplemental Figure S3). When Raptor $f / f l^{*} K s p C r e$ mice were timed mated with Raptor $f / f l$ females, we did not observe any offspring, despite plug-positive females. Only matings with Raptor fl/fl males with either Raptor fl/fl or Raptor fl/ $f * K s p C r e$ females produced offspring (Figure 2A). In contrast to their male counterparts female Raptor fl $f * K s p C r e$ mice were fertile, and litter sizes were virtually indistinguishable from those of Raptor $f / f l$ females (Figure 2A).

Computer-assisted sperm analysis showed a dramatically reduced progressive and nonprogressive motility in Raptor fl/ $f * K s p C r e$ mice, whereas Raptor flfl mice had normal motility variable values (Figure 2B). Indeed, virtually all sperm were immotile in Raptor $f / f f^{*} \mathrm{KspCre}$ mice (Figure 2B). Although bi-testis weight was undistinguishable between genotypes, both epididymis and ductus deferens and the vesicula seminalis had a strikingly lower weight in 3month-old knockout mice (Figure 2C).

At the light microscopic level seminiferous tubules in Raptor $f / f * K s p C r e$ mice appeared normal and showed an undisturbed germ cell development (Figure 3, A, B, E, and F). With the use of transmission electron microscopy we detected vacuolization in the germinal epithelium of Raptor $f / f t^{*} \mathrm{KspCre}$ mice, potentially representing a secondary event because of obstruction in distal sperm-transporting ducts, a finding not apparent in control mice (Figure 3, C, $\mathrm{D}, \mathrm{G}$, and $\mathrm{H}$ ).

Already at 1 month of age, light microscopy of the caput epididymidis showed fewer intraluminal spermatids in Raptor $f / f{ }^{*} K s p C r e$ mice compared with those of control mice (Figure 4, A and E); however, gross epithelial structure appeared normal. Transmission electron microscopy at this time point showed numerous intraluminal spermiophages and endocytosis of spermatozoa or destroyed fragments thereof into the epithelial layer of the epididymis in Raptor $f / f{ }^{*} \mathrm{KspCre}$ mice (Figure 4, B-D, F-I, and K). Furthermore, the occurrence of enlarged endosomal vesicles close to the apical membrane was observed in epithelial cells of the epididymis (Figure 4J). At 3 months of age we found increased amounts of epididymal epithelial cell detritus within the epididymal lumen and pyknotic cell nuclei within the epithelial layer (Figure 5, C-G, J, and K) compared with control mice (Figure 5, A and B). Ultrastructurally numerous spermiophages could be detected (Figure 5, H and I), whereas epithelial cells presented many nuclear inclusions and nuclear invaginations, indicating imminent apoptosis. In accordance with our histologic and ultrastructural analysis proliferation was increased approximately sixfold in the epithelial cell layer of the epididymis in knockout mice (Figure 5, L-N). Apoptosis was also strikingly increased within the epididymal epithelium of Raptor fl/f*KspCre mice (Figure 5, O-Q).

Macroscopically, the seminal vesicles of 3-month-old Raptor $f / f *$ KspCre mice were shrunken, less lobated, and severely indurated compared with age-matched wild-type males (Figure 6, A-C). These changes were recapitulated histologically, where epithelial fold formation was greatly reduced, and the epithelial cells themselves appeared

Figure 7 PEECs suggest mitochondrial impairment as a factor for epithelial dysfunction. A: With the use of outgrowth culture of finely minced epididymis, we established a PEEC system. B and C: $m T / m G$ reporter mouse shows that most cells ( $80 \%$ and $90 \%$ ) are of epithelial origin (green fluorescence, epithelial cell; red fluorescence, nonepithelial cell). D and E: In addition most of the cells express classic epithelial marker proteins, that is, cytokeratin 18 or E-cadherin (both green; red, ACTIN; blue, Hoechst 33342). F: Androgen receptor expression is maintained in PEECs. G and H: After treatment with rapamycin for 24 hours P-S6P intensity is dramatically reduced in PEECs. I: Western blot quantification of rapamycin-treated PEECs confirms this observation of decreased P-S6P levels. J and K: Analysis of the oxygen consumption rate of PEECs treated with rapamycin for 24 hours reveals an overall decreased metabolic capacity in terms of basal respiration, proton leak, and ATP-linked respiration. L-0: Localization of the outer mitochondrial membrane protein TOM20 is altered in PEECs treated with rapamycin for 72 hours. P-R: This is similar to the in vivo situation in which the mitochondrial AR as a marker for mitochondrial structure was reduced in knockout mice (areas highlighted in blue and red indicate individual mitochondria in WT and KO mice, respectively; yellow dotted lines indicate areas which are shown in higher magnification to the right.). $n=3$ from three different primary isolates (I-K); at least 600 individual mitochondrial sections averaged over 2 individual mice per genotype $(\mathbf{P}$ and $\mathbf{R})$. ${ }^{*} P<0.05,{ }^{* *} P<0.001$ by $U$ test $(\mathbf{R})$. Original magnification, $\times 6.7$ (magnified images in $\mathbf{P}$ and $\mathbf{Q}$ ). AR, aspect ratio; $C$ trl, control; DMSO, dimethyl sulfoxide; E-CAD, E-cadherin; Epi, epididymis; FCCP, carbonyl cyanide-4-(trifluoromethoxy)phenylhydrazone; GFP, green fluorescent protein; KO, knockout; Mitoch, mitochondrial; norm, normal; Tom, tomato; OCR, oxygen consumption rate; $\mathrm{PEEC}$, primary epididymal epithelial cell; P-S6P, phosphorylated S6-protein; Rapa, rapamycin; TUB, tubule; WT, wild-type. 

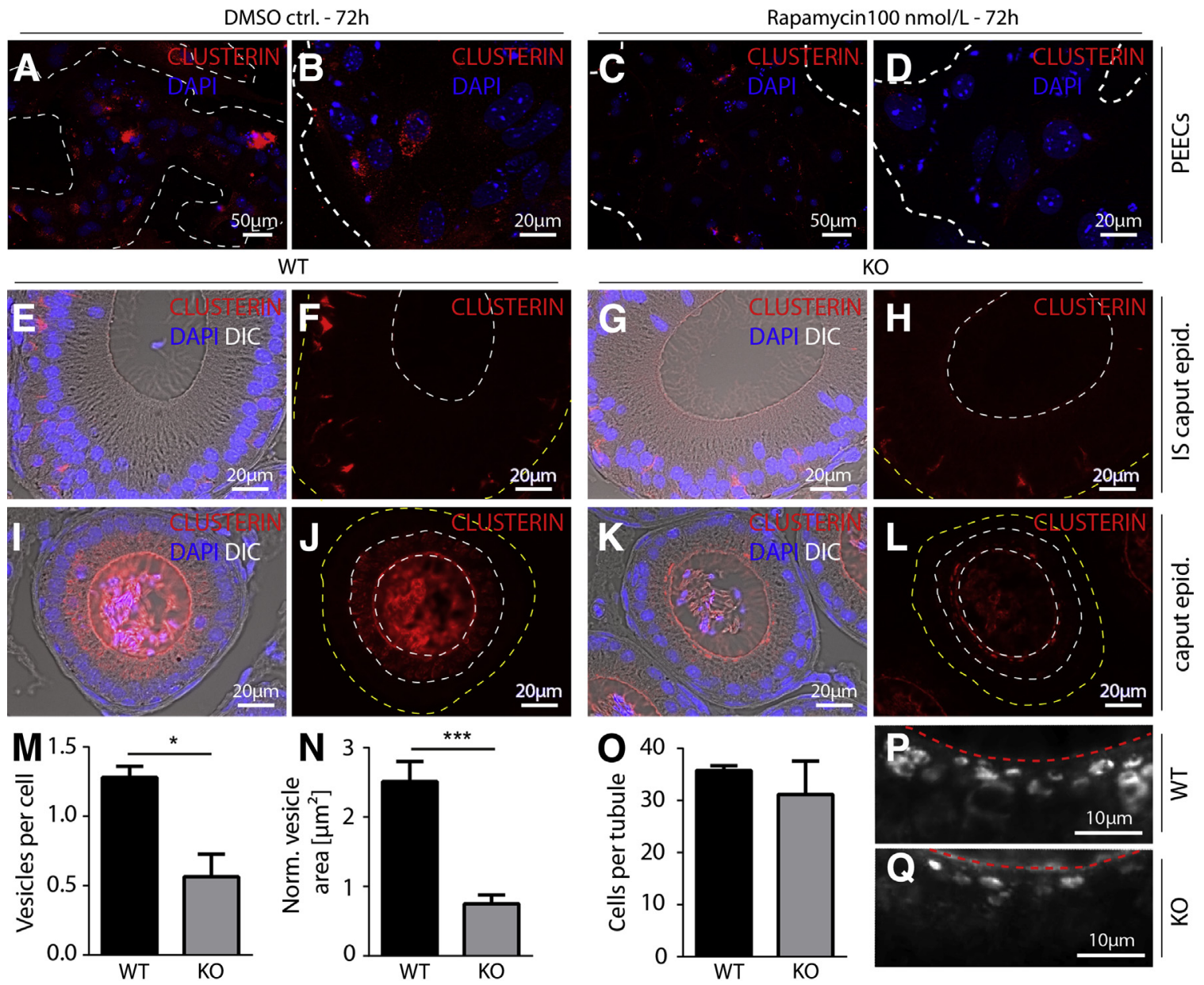

Figure 8 Secretional capacity as exemplified by CLUSTERIN is reduced in rapamycin-treated PEECs and Raptor fl/fl *KspCre mice in vivo. A-D: Treatment of PEECs with rapamycin for 72 hours decreases formation of CLUSTERIN-positive vesicles (white dotted lines indicate PEEC cell clusters). E-H: In the initial segment of the caput epididymis CLUSTERIN shows an expression in basal cells, which are reduced in Raptor $f / f l^{\star} K s p C r e$ mice (yellow dotted lines indicate the basal aspect of the respective tubule, whereas the white dotted lines indicate the inner lumen or secretory zone). I and J: Interestingly, in the corpus epididymis CLUSTERIN is detected in the apical aspects of epithelial cells and the lumen of the epididymal duct (yellow dotted lines indicate the basal aspect of the respective tubule, whereas the white dotted lines indicate the inner lumen or secretory zone). $\mathbf{K}$ and $\mathbf{L}$ : In this part of the epididymis (LUSTERIN expression also reduces in $\mathrm{KO}$ mice (yellow dotted lines indicate the basal aspect of the respective tubule, whereas the white dotted lines indicate the inner lumen or secretory zone). $\mathbf{M - 0}$ : Both vesicles per cell and the normalized vesicle area are reduced in Raptor $f / f l^{\star} K s p C r e$ mice, whereas the number of cells per epididymal section is not different. $\mathbf{P}$ and $\mathbf{Q}$ : Clusterin-positive vesicles close to the apical membrane show a smaller structure in $\mathrm{KO}$ mice compared with control mice (red dotted lines indicate the apical border of the respective tubular section). $n=3$ mice, between 9 and 12 individual tubular sections per animal (M-0). ${ }^{*} P<0.05$ by Student's $t$-test for vesicle per cell; ${ }^{* *} P<0.001$ vesicle area was tested with U-test. Ctrl, control; DIC, differential interference contrast; DMSO, dimethyl sulfoxide; epid, epididymis; IS, initial segment; KO, knockout; Norm, normal; PEEC, primary epididymal epithelial cell; WT, wild-type.

condensed compared with their control counterparts (Figure 6, D-G). Villous length of the epithelial cell layer was reduced by $40 \%$ in Raptor $f / f{ }^{*} K s p C r e$ mice, similarly to epithelial height that was reduced by $30 \%$ compared with control mice (Figure 6, H-J). Proliferation in the epithelial layer of Raptor $f / f f^{*} \mathrm{KspCre}$ mice was increased by $70 \%$ (Figure $6, \mathrm{~K}-\mathrm{M}$ ). The endoplasmatic reticulum marker CALNEXIN showed a widespread, homogenous staining pattern in control mice (Figure 6, N and $\mathrm{O}$ ), whereas punctate clustering was observed in knockout mice (Figure 6, P and Q). Ultrastructurally, wildtype cells showed an elaborated and densely packed endoplasmatic reticulum (Figure 6, R and $\mathrm{S}$ ) which was greatly reduced to small remnants in knockout mice (Figure 6, $\mathrm{T}$ and $\mathrm{U}$ ), mirroring our immunofluorescence findings.
To test whether our observations in Raptor $f / f l^{*} K s p C r e$ mice also have implications in the setting of therapeutic application of mTORC inhibition, we treated male mice with rapamycin $(10 \mathrm{mg} / \mathrm{kg}$ every 48 hours; mean trough level, $7.4 \mathrm{ng} / \mu \mathrm{L}$ ) for a period of 3 weeks. Indeed, we observed a striking weight reduction in all organs of the male reproductive tract (Supplemental Figure S4) compared with control mice treated with vehicle. Furthermore, histologic evaluation of the epididymal epithelium revealed numerous typical apoptotic and pyknotic nuclei (Supplemental Figure S4), a finding that was not apparent in control mice. These observations are in good agreement with our results after genetic deletion of mTORC1, underlining the translational relevance of our physiologic findings. 
To gain further mechanistic insights into the action of mTORC1 within the epithelium of the epididymis, we established a primary cell culture system (Figure 7A). With the use of the aforementioned $\mathrm{mT} / \mathrm{mG}^{*} K s p$ Cre mice and additional epithelial cell markers we could show that our dissociation approach yielded epididymal epithelial cells of high purity (Figure 7, B-F). Similar to Raptor deletion in vivo application of $100 \mathrm{nmol} / \mathrm{L}$ rapamycin for 24 hours led to a strong reduction in phosphorylation of PS6 (Figure 7, G-I), whereas androgen receptor expression was maintained (Supplemental Figure S3). Phospho-extracullular signal-regulated kinase showed a compensatory increase in rapamycin-treated primary cells, similar to the epithelial cell layer within the caput epididymis of Raptor $f / f t^{*} K s p C r e$ mice (Supplemental Figure S2, E-J). To evaluate the impact of mTORC1 inhibition on the general metabolic capacity of PEECs we analyzed oxygen consumption rates in combination with specific inhibitors (Figure $7 \mathbf{J}$ ). Here, we observed a reduced basal respiration rate and decreased levels of proton-linked and ATP-linked respiration (Figure 7, J and K). Altogether, these findings indicate a definite decrease in metabolic capacity of PEECs under rapamycin treatment. Visualization of mitochondria in PEECs with the use of immunofluorescence indicated an altered structure after rapamycin treatment (Figure $7, \mathrm{~L}-\mathrm{O}$ ). Interestingly, we also found a greatly reduced aspect ratio (used as an indicator of altered structure) in mitochondria of Raptor $f / f f^{*} K s p C r e$ epididymal epithelial cells compared with control mice (Figure 7, P-R). Taken together these in vivo and in vitro findings suggest that abrogation of mTORC1-dependent mitochondrial biogenesis and metabolic capacity by either genetic deletion or pharmacologic inhibition could at least in part explain the functional deficits observed in Raptor $\mathrm{fl} / \mathrm{f} \mathrm{*}^{*} \mathrm{KspCre}$ mice.

We finally analyzed the expression of known secretory epididymal proteins. Although the protease SERPINF1 and the protein CRISP1 did not show any major differences between genotypes (Supplemental Figure S5), CLUSTERINpositive vesicles appeared in an altered morphologic pattern in PEECs after 72 hours of rapamycin treatment (Figure 8, A-D). This altered expression of CLUSTERIN could also be demonstrated in Raptor $\mathrm{fl} / \mathrm{f} \mathrm{*}^{*} \mathrm{KspCre}$ mice. Although we observed a strong signal intensity for CLUSTERIN in basal cells of the initial segment of the caput epididymis, the number of basal cells appeared to be reduced in Raptor $\mathrm{fl} / \mathrm{f}{ }^{*} \mathrm{KspCre}$ mice (Figure 8, E-H). In the corpus epididymis of control mice CLUSTERIN was mainly detected in apical cellular compartments close to the epididymal duct lumen and within the epididymal duct itself (Figure 8, I and J). Its expression level was greatly reduced in Raptor $f / f f^{*} K s p C r e$ mice (Figure 8, K and L), indicating a disturbed secretory pattern in these mice. Quantification of this observation yielded a reduced number of vesicles per cell and a reduced normalized vesicle area in epithelial cells of the corpus epididymis in Raptor $f / f{ }^{*} K s p C r e$ mice; however, the number of cells per tubule diameter was not changed compared with control mice (Figure 8, M-Q).

\section{Discussion}

We here identified a novel, essential role for mTORC1 in regulating male fertility via non-testicular-mediated effects. Sperm maturation occurs along the different parts of the epididymis and occurs in parallel with modification of the testicular and epididymal fluid. Beside the secretion of several types of still mostly unknown protein-based components, the epithelium of the epididymis dramatically modulates the electrolyte composition of the testicular fluid. Among others there is acidification of the luminal $\mathrm{pH}$, increase in osmolality to hyperosmotic values, and a decrease in luminal $\mathrm{Ca}^{2+}$ concentration. ${ }^{20-22}$ These modifications are necessary for spermatozoa to withstand the milieu of the female reproductive tract and to swim the long distance from the cervix uteri to the oviduct. Aside from the epididymis, accessory sexual glands such as the seminal vesicle are essentially involved in male fertility. ${ }^{23}$ Approximately up to $50 \%$ of the ejaculate is secreted by seminal vesicles, and dysfunction in the secretory process might cause or at least contribute to male fertility problems. ${ }^{23}$ The striking reduction in organ weight of seminal vesicles in Raptor $f / f{ }^{*} \mathrm{KspCre}$ mice highlights the essential function of mTORC1 to maintain this specialized secretory epithelium. The observed regression phenotype seems to depend on the cell autonomous effects of MTORC1; however, no evidence was found for any hormonal dysbalances (androgen receptor expression was indistinguishable between genotypes and after in vitro mTORC1 inhibition). On the molecular level our study revealed that mTORC1 specifically regulates the metabolic capacity of EECs. The observed secretory defect of EECs is likely a direct consequence of the disturbed energy metabolism and the impaired protein translation machinery in mTORC1-deficient or -inhibited cells. In addition, the increase in apoptosis might indicate a reduced cellular stress adaptation after mTORC1 deletion/inhibition. Interestingly, epithelial cells of the epididymis and vesicula seminalis in Raptor $f / f f^{*}$ KspCre mice showed an increased proliferation rate despite mTORC1 deficiency. This could be because of the strong compensatory increase in phospho-extracullular signal-regulated kinase, which is a potent stimulator of cell proliferation. ${ }^{24}$

Observational clinical reports together with preclinical reproductive toxicity safety data unequivocally determined the risk of male subfertility to infertility under rapamycin treatment. ${ }^{4,6,8,25}$ Although these reports mainly focused on testicular alterations, other male reproductive organs were not studied in such detail. Inherent to their nature most of these reports failed to pinpoint the exact mechanism, owing to systemic delivery of the compound and variable comedications in patients. ${ }^{3,5}$ Strikingly, however, the description of oligospermia to azoospermia with reduced total sperm count and severely impaired motility fits well with our observations in a genetic animal model. ${ }^{3}$ With the use of a 
urogenital promotor that spares the testis, but efficiently targets the epididymis, ductus deferens, and associated sex glands was sufficient to render male mice infertile. Interestingly, although the Ksp promotor targets the oviduct and the endometrium in female mice, the effect on female fertility in Raptor $f / f l * K s p C r e$ mice was negligible. Although this is in contrast to the known role of dysregulated mTOR/AKT signaling in somatic cells of the female reproductive tract, at least one case report described successful pregnancy and live birth after systemic everolimus treatment. These observations could indicate that female fertility might be less susceptible to mTORC inhibitor therapy. ${ }^{26,27}$

In summary, we have identified a hitherto unknown, essential role of mTORC1 for male fertility via modification of extra-testicular organ function. mTORC1 regulates sperm modification during passage of the epididymis and directly controls glandular size and production of glandular fluids in the seminal vesicle. These findings do not only describe an important physiologic function of mTORC1 in the maintenance of extra-testicular reproductive biology but should also help to better understand the clinically relevant side effect of male infertility related to the use of mTORC1 inhibitors.

\section{Acknowledgments}

We thank Barbara Joch, Sigrun Nestel, Evelyn Wätzig, and Temel Kilic for expert technical assistance.

\section{Supplemental Data}

Supplemental material for this article can be found at http://dx.doi.org/10.1016/j.ajpath.2015.10.012.

\section{References}

1. Laplante M, Sabatini DM: mTOR signaling in growth control and disease. Cell 2012, 149:274-293

2. Calne RY, Collier DS, Lim S, Pollard SG, Samaan A, White DJ, Thiru S: Rapamycin for immunosuppression in organ allografting. Lancet 1989, 2:227

3. Zuber J, Anglicheau D, Elie C, Bererhi L, Timsit MO, MamzerBruneel MF, Ciroldi M, Martinez F, Snanoudj R, Hiesse C, Kreis H, Eustache F, Laborde K, Thervet E, Legendre C: Sirolimus may reduce fertility in male renal transplant recipients. Am J Transplant 2008, 8: 1471-1479

4. Bererhi L, Flamant M, Martinez F, Karras A, Thervet E, Legendre C: Rapamycin-induced oligospermia. Transplantation 2003, 76:885-886

5. Deutsch MA, Kaczmarek I, Huber S, Schmauss D, Beiras-Fernandez A, Schmoeckel M, Ochsenkuehn R, Meiser B, Mueller-Hoecker J, Reichart B: Sirolimus-associated infertility: case report and literature review of possible mechanisms. Am J Transplant 2007, 7:2414-2421

6. Rovira J, Diekmann F, Ramirez-Bajo MJ, Banon-Maneus E, Moya-Rull D, Campistol JM: Sirolimus-associated testicular toxicity: detrimental but reversible. Transplantation 2012, 93:874-879

7. Rey RA, Grinspon RP, Gottlieb S, Pasqualini T, Knoblovits P, Aszpis S, Pacenza N, Stewart Usher J, Bergada I, Campo SM: Male hypogonadism: an extended classification based on a developmental, endocrine physiology-based approach. Andrology 2013, 1:3-16
8. Fritsche L, Budde K, Dragun D, Einecke G, Diekmann F, Neumayer HH: Testosterone concentrations and sirolimus in male renal transplant patients. Am J Transplant 2004, 4:130-131

9. Tanwar PS, Kaneko-Tarui T, Zhang L, Teixeira JM: Altered LKB1/AMPK/TSC1/TSC2/mTOR signaling causes disruption of Sertoli cell polarity and spermatogenesis. Hum Mol Genet 2012, 21:4394-4405

10. Blume-Jensen P, Jiang G, Hyman R, Lee KF, O'Gorman S, Hunter T: Kit/stem cell factor receptor-induced activation of phosphatidylinositol 3'-kinase is essential for male fertility. Nat Genet 2000, 24:157-162

11. Farini D, La Sala G, Tedesco M, De Felici M: Chemoattractant action and molecular signaling pathways of Kit ligand on mouse primordial germ cells. Dev Biol 2007, 306:572-583

12. Mok KW, Mruk DD, Silvestrini B, Cheng CY: rpS6 Regulates bloodtestis barrier dynamics by affecting F-actin organization and protein recruitment. Endocrinology 2012, 153:5036-5048

13. Committee for the Update of the Guide for the Care and Use of Laboratory AnimalsNational Research Council: Guide for the Care and Use of Laboratory Animals: Eighth Edition. Washington, DC, National Academies Press, 2011

14. Bentzinger CF, Romanino K, Cloetta D, Lin S, Mascarenhas JB, Oliveri F, Xia J, Casanova E, Costa CF, Brink M, Zorzato F, Hall MN, Ruegg MA: Skeletal muscle-specific ablation of raptor, but not of rictor, causes metabolic changes and results in muscle dystrophy. Cell Metab 2008, 8:411-424

15. Shao X, Somlo S, Igarashi P: Epithelial-specific Cre/lox recombination in the developing kidney and genitourinary tract. J Am Soc Nephrol 2002, 13:1837-1846

16. Muzumdar MD, Tasic B, Miyamichi K, Li L, Luo L: A global doublefluorescent Cre reporter mouse. Genesis 2007, 45:593-605

17. Qu B, Gu Y, Shen J, Qin J, Bao J, Hu Y, Zeng W, Dong W: Trehalose maintains vitality of mouse epididymal epithelial cells and mediates gene transfer. PLoS One 2014, 9:e92483

18. Leir SH, Browne JA, Eggener SE, Harris A: Characterization of primary cultures of adult human epididymis epithelial cells. Fertil Steril 2015, 103:647-654.e1

19. Grahammer F, Haenisch N, Steinhardt F, Sander L, Roerden M, Arnold F, Cordts T, Wanner N, Reichardt W, Kerjaschki D, Ruegg MA, Hall MN, Moulin P, Busch H, Boerries M, Walz G, Artunc F, Huber TB: mTORC1 maintains renal tubular homeostasis and is essential in response to ischemic stress. Proc Natl Acad Sci U S A 2014, 111:E2817-E2826

20. Cornwall GA: New insights into epididymal biology and function. Hum Reprod Update 2009, 15:213-227

21. Weissgerber P, Kriebs U, Tsvilovskyy V, Olausson J, Kretz O, Stoerger C, Vennekens R, Wissenbach U, Middendorff R, Flockerzi V, Freichel M: Male fertility depends on $\mathrm{Ca}(2)+$ absorption by TRPV6 in epididymal epithelia. Sci Signal 2011, 4:ra27

22. Shum WW, Da Silva N, McKee M, Smith PJ, Brown D, Breton S: Transepithelial projections from basal cells are luminal sensors in pseudostratified epithelia. Cell 2008, 135:1108-1117

23. Gonzales GF: Function of seminal vesicles and their role on male fertility. Asian J Androl 2001, 3:251-258

24. Seger R, Krebs EG: The MAPK signaling cascade. FASEB J 1995, 9 : 726-735

25. Chen Y, Zhang Z, Lin Y, Lin H, Li M, Nie P, Chen L, Qiu J, Lu Y, Chen L, Xu B, Lin W, Zhang J, Du H, Liang J, Zhang Z: Long-term impact of immunosuppressants at therapeutic doses on male reproductive system in unilateral nephrectomized rats: a comparative study. Biomed Res Int 2013, 2013:690382

26. Tanaka Y, Park JH, Tanwar PS, Kaneko-Tarui T, Mittal S, Lee HJ, Teixeira JM: Deletion of tuberous sclerosis 1 in somatic cells of the murine reproductive tract causes female infertility. Endocrinology 2012, 153: 404-416

27. Margoles HR, Gomez-Lobo V, Veis JH, Sherman MJ, Moore J Jr: Successful maternal and fetal outcome in a kidney transplant patient with everolimus exposure throughout pregnancy: a case report. Transplant Proc 2014, 46:281-283 